\title{
Effect of cage tier and age on performance, egg quality and stress parameters of laying hens
}

\author{
A. Şekeroğlu ${ }^{1 \#}$, M. Duman ${ }^{2}$, Y. Tahtalı ${ }^{3}$, A. Yıldırım ${ }^{3}$ \& H. Eleroğlu ${ }^{4}$ \\ ${ }^{1}$ Department of Animal Production and Technologies, Faculty of Agricultural Sciences and Technologies, \\ University of Niğde, Niğde/Turkey \\ ${ }^{2}$ Bor Vocational High School, University of Nigde, Nigde/Turkey \\ ${ }^{3}$ Department of Animal Science, Faculty of Agriculture, University of Gaziosmanpaşa, Tokat/Turkey \\ ${ }^{4}$ Aşık Veysel Vocational High School, University of Cumhuriyet, Sivas/Turkey
}

(Received 9 December 2013; Accepted 6 August 2014; First published online 4 October 2014)

Copyright resides with the authors in terms of the Creative Commons Attribution 2.5 South African Licence.

See: http://creativecommons.org/licenses/by/2.5/za

Condition of use: The user may copy, distribute, transmit and adapt the work, but must recognise the authors and the South African Journal of Animal Science

\begin{abstract}
This study was conducted to investigate the effects of cage tier and age on performance characteristics of layer hybrids, egg quality and some stress parameters. Ninety laying hens (hybrid ATAK-S) of similar bodyweights were used in the experiment. They were housed in three-tier conventional battery cages (bottom, middle and top) with $600 \mathrm{~cm}^{2} /$ per bird. The experiment was conducted on hens from the age of 18 weeks to 42 weeks. Layers at the age of 18 weeks were randomly allocated to conventional three-tier battery cages with five replicates of six hens per treatment in a completely randomized design. In the bottom, middle and top tiers, 5\% age of yield was observed as 151, 146 and 156 days, respectively; $50 \%$ age of yield was 162.4, 158.6 and 161.8 days; $5 \%$ yield age bodyweight (BW) as 1597.8, 1460.5 and $1599.2 \mathrm{~g} ; 50 \%$ yield age BW as 1708.7, 1666.4 and $1671.7 \mathrm{~g}$, respectively. The effects of cage tiers on week $42 \mathrm{BW}$, feed conversion ratio $(\mathrm{FCR})$, tonic immobility $(\mathrm{TI})$, egg weight $(\mathrm{EW})$, egg yield (EY), and most external and internal quality traits of the hens' eggs were found to be insignificant. Except for shape index (SI) and albumen pH, internal and external quality traits of eggs were significantly affected by age of the hens. In addition, there were significant effects of age on the FCR, EY, EW and oviposition time. The effects of cage tier on tonic immobility (TI) in week 42 and viability were found to be insignificant, but $\mathrm{TI}$ in week 30 was found to be significant. It can be concluded that cage tier did not have significant effects on egg yield, egg quality and indicators of stress parameters studied in the experiment. However, these parameters were affected by the age of the hens at the beginning of the laying period.
\end{abstract}

Keywords: Cage tiers, layer hybrids, hybrids age, egg quality

\#Corresponding author: ahmet.sekeroglu@nigde.edu.tr

\section{Introduction}

Egg quality and animal welfare can be affected seriously by production systems. Poultry products and their quality are affected significantly by genetic and ecological conditions such as the indoor environment of the poultry house (Bell \& Weaver, 2002; Ahmed \& Singh, 2007).

Battery cage systems are commonly used in poultry houses to provide some commercial and health benefits (Appleby, 1998; Rodenburg et al., 2005; Vits et al., 2005). However, battery cages may increase bird stress according to welfare perceptions (Hughes et al., 1993; Nicol, 1995; Vestergaard et al., 1997; Tauson, 1998; Onbasilar \& Aksoy, 2005; Ledvinka et al., 2012). Previous researchers reported significantly different performances for laying hens in caged houses because of varying housing systems and indoor environmental conditions of the poultry house (Duncan, 2001; De Boer \& Cornelissen, 2002; Awoniyi, 2003). Therefore, optimal environmental conditions should be provided in caged houses with sufficient quality and quantity of equipment (Karaman et al., 2013). Environmental conditions are not the same in every part of the caged layer house, and differences in microenvironments such as in ventilation, lighting and temperature might occur among cage tiers. The stress exerted by cages on production and animal welfare has been investigated extensively by many researchers (Carey, 1987; Carey et al., 1995; Patterson \& Siegel, 1998; Carmichael et al., 1999; Onbasilar \& Aksoy, 2005), but the impacts of varying microenvironments of cage tier 
on performance have seldom been investigated. External and internal quality of eggs are dependent on genotype and environmental factors such as housing system, oviposition time, age, ambient temperature and nutrition, as well as their interactions (Charvátová \& Tůmová, 2010; Tůmová \& Gous, 2012). External egg quality, namely egg weight, poorer and variable eggshell quality, and shape index, and internal egg quality, namely proportion of yolk, albumen and lipid, depend on the age of laying hens (Rizzi \& Chiericato, 2005; Johnston \& Gous, 2007; Tůmová \& Ledvinka, 2009; Charvátová \& Tůmová, 2010). Egg weight, eggshell content, albumen height and albumen $\mathrm{pH}$ are affected by interactions between the age of laying hens, oviposition time and housing system (Van den Brand et al., 2004; Tưmová et al., 2011).

This study was carried out in a poultry house to evaluate the effects of cage tier and age of hens on animal performance (egg yield, egg quality, feed consumption, and live weight) at the beginning of lay during the winter season.

\section{Materials and Methods}

This research was conducted in an experimental poultry house of the Department of Animal Science, Gaziosmanpaşa University, Tokat, Turkey. Ninety laying hens (hybrid, ATAK-S) of similar bodyweights were used in the experiments, starting when the hens were 18 weeks old and ending when they were 42 weeks old. Birds used in the experiment were cared for under the guidelines in the "Guide for the Care and Use of ATAK-S Brown Hybrid Laying Hens in the Poultry Research Institute", Ankara, Turkey. The experiment was approved by the Animal Ethics Committee (2011 HADYEK-043).

The poultry house contained conventional battery cages arranged in a three-tier design, namely bottom, middle and top. A cage provided $600 \mathrm{~cm}^{2}$ per bird. At 18 weeks of age, the hens were randomly allocated to the treatments, the three tiers, with five replicates of six hens per treatment in a completely randomized design.

The long axis of the poultry house was oriented east to west. The dimensions of the house were $30 \times$ $8 \times 2.7 \mathrm{~m}(\mathrm{~L} \times \mathrm{W} \times \mathrm{H})$ with a ridge height of $1.7 \mathrm{~m}$. Natural ventilation was provided through six air outlets $\left(0.48 \mathrm{~m}^{2}\right.$ each) over the ridge, and 20 windows $(50 \times 120 \mathrm{~cm}$ each) over the long axis of the building. The building had automated watering, feeding and litter removal systems. There were two double-sided cage blocks, and each block had three tiers. The base dimensions of the galvanized wire cages were $60 \times 60 \mathrm{~cm}$, $45.5 \mathrm{~cm}$ front height and $41 \mathrm{~cm}$ rear height. Heating was not provided during the research period, and ventilation was kept at a constant level. Lighting was provided by 20 ordinary light bulbs (each with $25 \mathrm{~W}$ and at a height of $1.80 \mathrm{~cm}$ ) without light traps. The lighting intensity was $3.13 \mathrm{~W} \mathrm{~m} \mathrm{~m}^{-2}$. Following sexual maturation, the lighting was gradually increased to $16 \mathrm{~h}$ between 18 and 23 weeks of age. Constant $16 \mathrm{~h}$ lighting was applied afterwards until the end of the experiments (Efil \& Sarica, 1998).

Feed and water were supplied ad libitum throughout the experimental period. Feed consumption was recorded weekly and calculated as g per hen per day. From 18 weeks of age the hens were fed a diet containing $11.29 \mathrm{MJ} \mathrm{ME} / \mathrm{kg}$ and $160 \mathrm{~g}$ crude protein/ $\mathrm{kg}$. Hens were weighed individually at 18,30 and 42 weeks of age with an electronic balance $( \pm 0.01 \mathrm{~g})$. Feed efficiency was calculated as $\mathrm{g}$ feed per $\mathrm{g}$ egg. Viability was observed visually and recorded daily throughout the experimental period.

Eggs from each replicate were collected three times a day, at 09:00, 13:00 and 15:00, and weighed with an electronic balance at the same time every day to calculate hen-day egg production (HDEP) and henhouse egg production (HHEP), percentage hen-day egg production (HDP) and percentage henhouse egg production (HHP), and egg weight (EW) from 24 to 42 weeks of age. In addition, age (day) at $5 \%$ and $50 \%$ egg production and bodyweights at $5 \%$ and $50 \%$ egg production age were recorded.

On the last day of every three weeks $30 \%$ of the eggs were randomly selected from each experimental group to assess egg quality. An average of three measurements (3 times) were taken at the equator, blunt edge and pointed edge of the egg and recorded for lightness $\left(L^{*}\right)$, redness $\left(a^{*}\right)$ and yellowness $\left(b^{\star}\right)$ of the eggshell with a Minolta CR400 chromameter (Konica Minolta Sensing Inc., Osaka, Japan). Colour differences $\left(\Delta E^{*}\right)$ were calculated using the $L^{*}, a^{*}, b^{*}$, and expressed as the colour of the egg (Ingram et al., 2008).

The eggs were analysed for interior and exterior quality traits, weight, shell surface area, specific gravity, shape index, shell-breaking strength, shell weight, thickness, albumen index, yolk index, Haugh unit (HU) score and albumen pH (Nordstrom \& Ousterhout, 1982; Silversides, 1994; Anderson et al., 2004; TSE, 2009; Sekeroglu et al., 2010). Egg specific gravity was determined with graded salt solutions ranging from $1.069 \mathrm{~g} / \mathrm{cm}^{3}$ to $1.099 \mathrm{~g} / \mathrm{cm}^{3}$ with gradations of $0.003 \mathrm{~g} / \mathrm{cm}^{3}$, as described by Hamilton (1982). After that, shellbreaking strength was measured with a shell strength device with a spiral pressure system (Fujihara, Saitama, Japan). Subsequently, the eggs were broken one by one onto a glass plate. Allowing a waiting period of 5 min the albumen and yolk heights were measured with a tripod micrometer, and the long and short diameters of albumen, and diameter of yolk with a digital calliper $( \pm 0.001 \mathrm{~mm})$. The formulas of egg quality traits are presented in Table 1 . Shell thickness was measured with a calliper as an average of three 
measurements taken at the equator, the blunt edge and pointed edge of the egg without membrane. The yolk colour was determined with a DSM (2013) yolk colour fan (DSM Nutritional Products Ltd., Basel, Switzerland), which ranges from pale yellow at score 1 to dark orange at score 15 , according to the CIE standard colorimetric system.

At 30 and 42 weeks of age, 10 hens from each cage (a total of 30 hens) were selected and used to perform a tonic immobility $(\mathrm{TI})$ test. The $\mathrm{TI}$ tests were run by two experimenters in a room adjacent to the rearing room. A bird was tested individually by placing it on its back on a U-shaped wooden cradle and restrained for $15 \mathrm{~s}$ (Mills \& Faure, 1991). The observer sat within sight of the bird, approximately $1 \mathrm{~m}$ away, with his or her eyes fixed on the bird to give fear-inducing properties of eye contact. The duration of TI was recorded (i.e., the time until the bird stood up). If an attempt of induction was unsuccessful (no TI or TI lasting less than $10 \mathrm{~s}$ ), the experimenter immediately resumed the induction procedure. If $\mathrm{TI}$ could not be induced after five attempts, the bird was deemed not to be susceptible and its $\mathrm{TI}$ duration score was recorded as 0 . If the bird did not stand after $10 \mathrm{~min}$, a maximum score of $600 \mathrm{~s}$ was recorded for TI duration (Campo \& Prieto, 2009; Dávila et al., 2011).

Blood samples were collected at the end of experiment. Two drops of blood were collected from the $V$. cutanea ulnaris, and blood smears were made on glass slides. Slides were stained using the May Grunwald-Giemsa staining method (Campbell, 1995). One hundred leukocytes, including heterophils and lymphocytes, were counted on each slide. The $\mathrm{H} / \mathrm{L}$ ratio was calculated by dividing the number of heterophils by the number of lymphocytes.

The data were subjected to an analysis of variance (ANOVA) using SPSS 16.0 software for Windows (SPSS Inc. Chicago, IL. USA). The differences between groups were determined by Duncan's multiple-range tests. All values were presented as means and standard errors of the mean, and significance levels were set as $P<0.05$ and $P<0.01$.

Table 1 Formulas of some egg quality traits

\begin{tabular}{|c|c|c|}
\hline Criteria & Abbrev. & Equation \\
\hline${ }^{1}$ Hen-day egg production , \% & HDP & $\begin{array}{l}\text { (No. of eggs produced during period/No. of hen day in the period) } x \\
100\end{array}$ \\
\hline${ }^{1}$ Hen-house egg production, $\%$ & $\mathrm{HHP}$ & $\begin{array}{l}\text { [(No. of eggs produced during period/No. live hens in initial } \\
\text { experiment }) /(\text { days })] \times 100\end{array}$ \\
\hline${ }^{2}$ Hen-house egg production (egg/hen) & HHEP & $\begin{array}{l}\text { (No. of eggs produced during period/No. of hens present at } 24 \\
\text { weeks) }\end{array}$ \\
\hline${ }^{2}$ Hen-day egg production (egg/hen) & HDEP & $\begin{array}{l}\text { (No. of eggs produced during period/No. of hen day in the period) } x \\
\text { days }\end{array}$ \\
\hline${ }^{3}$ Shape index, $\%$ & $\mathrm{SI}$ & (Egg width/egg length ) $\times 100$ \\
\hline${ }^{3}$ Yolk index, \% & $\mathrm{YI}$ & (Yolk height/yolk diameter) $\times 100$ \\
\hline${ }^{3}$ Albumen index, \% & Al & $\begin{array}{l}\text { [Albumen height/((long diameter of albumen }+ \text { short diameter of } \\
\text { albumen) } / 2)] \times 100\end{array}$ \\
\hline${ }^{4}$ Egg surface area $\left(\mathrm{cm}^{2}\right)$ & ES & $3.9782 \times$ egg weight $t^{0.70}$ \\
\hline${ }^{5}$ Shell weight $(g)$ & SW & (2.0341 x egg weight) - [(2.1014 x egg weight)/specific gravity] \\
\hline${ }^{6}$ Haugh unit (score) & $\mathrm{HU}$ & $100 \log \left(\right.$ albumen height+7.57-1.7 $\mathrm{W}^{0.37}$ ) \\
\hline Colour difference & $\Delta \mathrm{E}^{*}$ & $\left(L^{2}+a^{2}+b^{2}\right)^{1 / 2}$ \\
\hline
\end{tabular}

\section{Results and Discussion}

All hens stayed healthy over the experimental period. No birds were culled and medical intervention was not applied to any bird.

The results of bodyweight obtained from the various tiers are presented in Table 2 . The effects of cage tier on bodyweight of the laying hens at the initial stage of the experiment (hens at 18 weeks of age) and at 42 weeks of age were not significantly different (Table $2, P>0.05)$, but, there was a significant $(P<0.05)$ difference in bodyweight of the hens between tiers at 30 weeks of age. Likewise, tier (bottom, middle, top) of cage had different effects $(P<0.01)$ on bodyweight at 5\% yield age for hens, except $50 \%(P>0.05)$. Bodyweight on the bottom tier were higher than on the top tier. The cage floors from bottom to top resulted in a lower bodyweight. However, this effect was not present at 42 weeks and $50 \%$ yield age. These findings are in agreement with the results of earlier studies (Onbasilar \& Aksoy, 2005; Bozkurt et al., 2006) who reported no differences in bodyweight among tiers at the end of the experiment. Current findings are in agreement 
with the results of Bozkurt et al. (2006), indicating an adverse impact on laying performance at the top tier. These effects were clearer when the laying hens became older. The higher light intensity in the top tier might have resulted in stress on the birds housed there, as indicated by Jackson \& Waldroup (1987) and Elston et al. (2000). In contrast, Grover et al. (1972) claimed that bodyweight of layers maintained on the top cage tier was higher than those on lower tiers. As shown in Table 2, no difference was recorded in laying hens allocated to different tiers in age at $5 \%$ and $50 \%$ egg production $(P>0.05)$. Nazlıgül et al. (1995) reported that cage row effects were significant on the top rows. Viability was similar in laying hens in the bottom, middle and top rows of cages through laying periods and all treatments had less than $5 \%$ mortality. ATAK-S laying hens were consistently within the viability values recommended by management. When hens were housed in top-row cages, mortality was numerically higher. Other researchers reported similar results that cage tier (Adams \& Jackson, 1970; Grover et al., 1972; Onbasilar \& Aksoy, 2005) had no effect on viability. These results are contrary to findings of Bozkurt et al. (2006), which indicated that mortality increased with top and bottom tiers in 4- to 16-week-old pullets.

Table 2 Effects of cage tier on bodyweight, age of yield and viability of laying hens

\begin{tabular}{|c|c|c|c|c|c|}
\hline \multirow{2}{*}{ Parameters } & \multicolumn{4}{|c|}{ Cage tiers } & \\
\hline & Bottom & Middle & Top & SEM & \\
\hline \multicolumn{6}{|l|}{ Bodyweight (BW), g } \\
\hline Initial bodyweight & 1187 & 1187 & 1189 & 2.55 & NS \\
\hline 30. week old BW & $1868^{\mathrm{b}}$ & $1799^{\mathrm{ab}}$ & $1780^{\mathrm{a}}$ & 17.13 & * \\
\hline 42. week old BW & 1963 & 1946 & 1942 & 16.44 & NS \\
\hline $5 \%$ yield age $B W$ & $1598^{b}$ & $1461^{a}$ & $1599^{b}$ & 12.66 & ** \\
\hline $50 \%$ yield age BW & 1709 & 1666 & 1672 & 9.95 & NS \\
\hline \multicolumn{6}{|l|}{ Age of yield (days) } \\
\hline $5 \%$ & 151 & 146 & 156 & 2.89 & NS \\
\hline $50 \%$ & 162 & 159 & 162 & 0.31 & NS \\
\hline Viability (\%) & 100 & 100 & 96.67 & 1.11 & NS \\
\hline
\end{tabular}

SEM: standard error of mean, NS: not significant, $P>0.05$; ${ }^{*} P<0.05 ;{ }^{\star \star} P<0.05$.

Means within a row followed by different superscripts differ significantly.

The findings obtained on egg production and quality from different tier levels are presented in Table 3. The results of this study indicated that cage tier position had no effect on feed efficiency, henhouse egg production, hen-day egg production and egg weight. Fidan \& Nazlıgül (2012) reported that feed efficiency was not significantly different among the tiers in the Denizli genotype. These results are in conflict with the findings of Nazlıgül et al. (1995), who found significant differences between laying hens of different genetic origin. On the other hand, these findings were similar to the findings of Onbasilar \& Aksoy (2005), Yıldız et al. (2006) and Sahin (2012) who reported that cage level position did not affect hen-day egg production. Current findings are parallel to those of Yıldız et al. (2006) and Sahin (2012), who claimed that the effect of tier level was not observed in egg weight of ISA brown and Lohmann layers. Conversely, Fidan \& Nazlıgül (2012) observed that egg weight was significantly influenced by cage tier. In the Denizli genotype they found the highest egg weights from the top and middle tiers (51.3 and 51.0), respectively. Carmichael et al. (1999) recorded higher performance when birds were reared in the upper tier cage.

There was no significant $(P>0.05)$ difference among cage tiers in terms of shape index, specific gravity, shell-breaking strength, eggshell thickness and albumen and yolk indices, Haugh unit score, shell weight, egg surface area, albumen $\mathrm{pH}$ and eggshell colour $\Delta \mathrm{E}^{*}$. Specific gravity values of ATAK-S brown laying hens ranged from 1.086 to 1.088 and egg quality characteristics were independent of cage tier level. These results corroborate the studies of Yıldız et al. (2006) and Sahin (2012), who observed that tier level did not affect shape index and eggshell thickness in laying hen eggs. Similarly, the studies conducted by Wells (1972), Onbasilar \& Aksoy (2005) and Sahin (2012), shell-breaking strength of eggs from different tiers was similar. Hens located in the bottom tier had numerically the highest Haugh unit score, albumen and yolk index $(P>0.05)$. These results agree with those reported by Yıldız et al. (2006), who found no significant effect of cage tier on Haugh unit score, albumen and yolk index. Similarly, some researchers found no 
differences in egg Haugh unit score of cage tier (Adams \& Jackson, 1970; Onbasilar \& Aksoy, 2005). Albumen quality is an important indicator of egg freshness, and significant for the egg processing industry (Jin et al., 2011). Silversides \& Villeneuve (1994) claimed that pH is a useful means of describing changes in albumen quality over time during storage. However, albumen $\mathrm{pH}$ was not affected by cage tier and can be used to measure egg freshness. Overall, albumen $\mathrm{pH}$ varied between 8.62 and 8.65, which is in agreement with data reported for ATAK-S laying hens by Sekeroglu et al. (2010) and Yıldırım et al. (2013; 2014). The $\Delta \mathrm{E}^{*}$ values of the eggshell in each tier indicated a high uniformity of eggshell pigmentation. The average $\Delta \mathrm{E}^{*}$ values of ATAK-S brown eggshells from 20-week-old hens in tiers ranged between 71.8 and 72.5 . In the present study, the values were similar for ATAK-S brown eggs, which are consistent with previous results (Yıldırım et al., 2013). Shell colour is usually affected by genetic background, season of lay, nutrition, diseases, all kinds of stimuli and drug, etc. (Wei et al., 1992, Yang et al., 2009; Yıldırım et al., 2013; 2014).

Table 3 Effects of cage tier on performance, yield and egg quality traits of laying hens

\begin{tabular}{lccccc}
\hline \multirow{2}{*}{ Parameters } & \multicolumn{5}{c}{ Cage tiers } \\
\cline { 2 - 3 } & Bottom & Middle & Top & SEM \\
\hline Egg production (24-42 week) & & & & \\
$\quad$ Feed efficiency (g feed/g egg) & 2.26 & 2.28 & 2.30 & 0.03 & NS \\
Henhouse egg production (\%) & 84.7 & 84.4 & 83.0 & 1.09 & NS \\
Hen-day egg production (\%) & 84.7 & 84.4 & 83.4 & 1.03 & NS \\
Henhouse egg production (egg/hen) & 112.6 & 112.2 & 110.9 & 1.37 & NS \\
Hen-day egg production (egg/hen) & 112.6 & 112.2 & 110.3 & 1.45 & NS \\
Egg weight (g) & 60.6 & 60.1 & 60.4 & 0.23 & NS \\
\hline Egg quality characteristics & & & & \\
Shape index (\%) & 76.6 & 76.5 & 76.7 & 0.19 & NS \\
Specific gravity (g/cm ${ }^{3}$ ) & 1.086 & 1.088 & 1.087 & 0.001 & NS \\
Shell breaking strength (kg/cm ${ }^{2}$ ) & 2.32 & 2.48 & 2.26 & 0.06 & NS \\
Eggshell thickness (mm) & 0.34 & 0.35 & 0.34 & 0.002 & NS \\
Albumen index (\%) & 12.04 & 11.74 & 11.67 & 0.18 & NS \\
Yolk index (\%) & 44.9 & 44.8 & 45.3 & 0.22 & NS \\
Haugh unit (score) & 95.2 & 94.3 & 94.2 & 0.51 & NS \\
Shell weight (g) & 6.14 & 6.20 & 6.06 & 0.05 & NS \\
Surface area (cm ${ }^{2}$ ) & 71.36 & 70.05 & 70.01 & 0.36 & NS \\
Albumen pH & 8.62 & 8.63 & 8.65 & 0.01 & NS \\
Eggshell colour $\Delta \mathrm{E}^{*}$ & 71.83 & 72.49 & 71.90 & 0.19 & NS \\
& & & & &
\end{tabular}

SEM: standard error of mean, NS: not significant, $P>0.05$.

The effects of age on performance, yield and egg quality traits of laying hens are given in Table 4 . The results indicated that hen age affected $(P<0.01)$ feed efficiency, henhouse egg production percentage, henday egg production percentage and egg weight. The feed efficiency at $24-29$ weeks of age was higher (2.42 vs. 2.18 and 2.24; $P<0.01$ ) than those of $30-35$-week-old and $36-42$-week-old groups. Henhouse (\%) and hen-day (\%) egg production at 24 - 29 weeks of age were lower than those of $30-35$ and 36 - 42 weeks of age. In the current experiment, laying performance increased until the age of 28 weeks. Rizzi \& Chiericato (2005), Baumgartner et al. (2007), Johnston \& Gous (2007) and Zita et al. (2009) showed that egg weight increases with the age of hens. Conversely, Zemková et al. (2007) demonstrated that egg weight was not influenced significantly by the age of hens.

The ATAK-S produced regular weight eggs $(56.5 \mathrm{~g})$ at the beginning of the current experiment, but produced the heaviest eggs $(63.2 \mathrm{~g})$ at the end of the experiment. Likewise, there were significant differences between ages in terms of specific gravity, shell-breaking strength, eggshell thickness, albumen and yolk index, Haugh unit score, shell weight, egg surface area and eggshell colour $\Delta \mathrm{E}^{*}(P<0.05)$, except 
shape index and albumen $\mathrm{pH}(P>0.05)$. Specific gravity, albumen index, yolk index and Haugh unit score variables decreased with age in the ATAK-S genotype $(P<0.01)$.

Table 4 Effects of age on performance, yield and egg quality traits of laying hens

\begin{tabular}{|c|c|c|c|c|c|}
\hline \multirow{2}{*}{ Parameters } & \multicolumn{4}{|c|}{ Age groups } & \multirow{2}{*}{$P$} \\
\hline & 24 - 29 weeks & 30 - 35 weeks & 36 - 42 weeks & SEM & \\
\hline \multicolumn{6}{|l|}{ Egg production } \\
\hline Feed efficiency (g feed/g egg) & $2.42^{\mathrm{b}}$ & $2.18^{\mathrm{a}}$ & $2.24^{\mathrm{a}}$ & 0.02 & ** \\
\hline Hen-house egg production (\%) & $79.8^{\mathrm{a}}$ & $87.4^{\mathrm{b}}$ & $85.1^{\mathrm{b}}$ & 0.89 & *** \\
\hline Hen-day egg production (\%) & $79.8^{\mathrm{a}}$ & $87.4^{\mathrm{b}}$ & $82.3^{\mathrm{b}}$ & 0.98 & 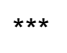 \\
\hline Egg weight (g) & $56.5^{\mathrm{a}}$ & $61.0^{\mathrm{b}}$ & $63.2^{\mathrm{c}}$ & 0.23 & *** \\
\hline \multicolumn{6}{|l|}{ Egg quality characteristics } \\
\hline Shape index & 76.6 & 77.1 & 76.3 & 0.19 & NS \\
\hline Specific gravity $\left(\mathrm{g} / \mathrm{cm}^{3}\right)$ & $1.089^{b}$ & $1.086^{\mathrm{a}}$ & $1.086^{\mathrm{a}}$ & 0.00 & ** \\
\hline Shell breaking strength $\left(\mathrm{kg} / \mathrm{cm}^{2}\right)$ & $2.16^{\mathrm{a}}$ & $2.29^{\mathrm{ab}}$ & $2.55^{b}$ & 0.06 & * \\
\hline Eggshell thickness (mm) & $0.33^{\mathrm{a}}$ & $0.34^{\mathrm{a}}$ & $0.35^{\mathrm{b}}$ & 0.00 & $* * *$ \\
\hline Albumen index (\%) & $12.87^{\mathrm{c}}$ & $12.04^{b}$ & $10.9^{\mathrm{a}}$ & 0.18 & $* \star \star$ \\
\hline Yolk index (\%) & $46.2^{\mathrm{b}}$ & $44.4^{\mathrm{a}}$ & $44.5^{\mathrm{a}}$ & 0.22 & ** \\
\hline Haugh unit (score) & $97.9^{c}$ & $95.2^{\mathrm{b}}$ & $91.6^{\mathrm{a}}$ & 0.50 & $* * *$ \\
\hline Shell weight (g) & $5.80^{\mathrm{a}}$ & $6.12^{\mathrm{b}}$ & $6.40^{\mathrm{c}}$ & 0.05 & $* \star \star$ \\
\hline Surface area $\left(\mathrm{cm}^{2}\right)$ & $66.3^{\mathrm{a}}$ & $70.6^{\mathrm{b}}$ & $73.5^{\mathrm{c}}$ & 0.36 & $\star * \star *$ \\
\hline Albumen $\mathrm{pH}$ & 8.62 & 8.62 & 8.67 & 0.01 & NS \\
\hline Eggshell colour $\Delta \mathrm{E}^{*}$ & $73.0^{\mathrm{b}}$ & $70.8^{\mathrm{a}}$ & $72.4^{\mathrm{b}}$ & 0.19 & *** \\
\hline
\end{tabular}

SEM: standard error of mean, NS: not significant, $P>0.05$; ${ }^{*} P<0.05$; ${ }^{\star \star} P<0.01 ;{ }^{\star \star \star}, P<0.001$.

Means within a row followed by the different superscripts differ significantly.

The highest specific gravity, albumen and yolk index and haugh unit score were observed at 24 and 29 weeks of age. Zita et al. (2009) confirmed that the albumen and yolk indices significantly decreased with age in ISA Brown, Hisex Brown and Moravia BSL hens, which is in agreement with the current result. On the other hand, eggshell quality increased $(P<0.01)$ with age in the ATAK-S genotype. The highest shellbreaking strength, eggshell thickness, shell weight and surface area were observed between 36 and 42 weeks of age. Eggshell thickness and strength improved in all age periods. Yannakopoulos \& TserveniGousi (1987) and Zita et al. (2009) observed that the eggshell thickened with the hens' age, which is in agreement with the current findings. The results of the present experiment confirm with the findings of Zita et al. (2009), who found a similar thicker eggshell at $20-26$ weeks and $36-42$ weeks of age in eggs of Hisex Brown and Moravia BSL. It could be concluded that all egg quality characteristics measured in the present study depended on age of layer, except shape index and albumen $\mathrm{pH}$.

Table 5 summarizes the effect of cage tier level on laying hen welfare parameters. TI durations of the hens were significantly different during the initial 30 weeks. However, at the end of experiment this effect did not reflect on tonic immobility of layers between tiers. At 30 weeks the TI duration of laying hens in the bottom cage tier was lower than that of the top cage tier (89.7 vs. $162.6 \mathrm{~s}$ ). As seen from Table 5, laying hens in the top cage tier showed more fear stress than those of the bottom tier. This could suggest that exposing birds to continuous light in the top cage tier made them more stressed and fearful according to the TI measurement. Campo \& Prieto (2009) suggested that the utilization of TI as biological indicator of wellbeing, fear and stress may not be useful in all extreme conditions, especially in those including pain. However, TI duration has been widely described as a good predictor of the level of fearfulness in domestic chickens (Jones, 1986).

The ratio of heterophils to lymphocytes in the bottom tier was numerically higher ( 0.73 vs. 0.58 and $0.57 ; P>0.05)$ than those of the middle and top tier groups. This condition could be explained by the elevated concentration of corticosterone in blood circulation, which in turn causes an increase in heterophil 
count and a decline in lymphocyte count (Siegel, 1985; Onbasilar \& Aksoy, 2005). The results obtained in the present study are in agreement with the findings of a previous study (Onbasilar \& Aksoy, 2005).

Table 5 Effects of cage tier on welfare of laying hens

\begin{tabular}{|c|c|c|c|c|c|}
\hline \multirow{2}{*}{ Parameters } & \multicolumn{4}{|c|}{ Cage tiers } & \multirow{2}{*}{$P$} \\
\hline & Bottom & Middle & Top & SEM & \\
\hline \multicolumn{6}{|c|}{ Tonic immobility (s) } \\
\hline 30. week & $89.7^{a}$ & $119.0^{\mathrm{ab}}$ & $162.6^{b}$ & 12.87 & * \\
\hline 42. week & 156.0 & 149.8 & 155.5 & 13.40 & NS \\
\hline$H / L^{1}$ & 0.73 & 0.58 & 0.57 & 0.15 & NS \\
\hline
\end{tabular}

${ }^{\mathrm{T}} \mathrm{H} / \mathrm{L}$ : heterophil/lymphocyte ratio, NS: not significant, ${ }^{*} P<0.05$.

Means within a row followed by the different superscripts differ significantly.

Table 6 reports the effect of cage tier and age on oviposition time of ATAK-S laying hens. In general, hens in the bottom cage tier had higher $(P<0.05)$ morning values than those in the other tiers. Conversely, this effect was in favour of the other layers (middle and top tier) at midday $(P<0.05)$. Finally, there is no effect of cage tier in terms of evening $(P>0.05)$. Egg weight and eggshell quality characteristics vary according to the oviposition time. These results are consistent with those of several previous studies that indicated that percentage eggs laid early in the morning were higher than later in the day (Tưmová et al., 2007; Yıldırım et al., 2013). Likewise, there were significant differences between ages in terms of oviposition time. Similarly all ages were higher $(P<0.01)$ than those at other times of the day, midday and evening. The hen-day egg production percentage of thirty- to thirty-five-week-old hens were higher than those at other ages $(24-29$ weeks and $36-42$ weeks) in the morning $(P<0.01)$. In terms of morning oviposition time, percentage of egg produced was higher at 30 - 35 weeks of age because this age showed the peak period of egg production in laying hens from the start until 36 - 42 weeks age of laying.

Table 6 Effects of cage tier and age on oviposition time

\begin{tabular}{|c|c|c|c|c|c|}
\hline & \multirow{2}{*}{ Parameters } & \multicolumn{3}{|c|}{ Oviposition time (Hen-day egg production, \%) } & \multirow{2}{*}{$P$} \\
\hline & & Morning (09:00) & Midday (13:00) & Evening (15:00) & \\
\hline \multirow{5}{*}{ Tiers } & Bottom & $70.5^{\mathrm{B}, \mathrm{c}}$ & $22.2^{\mathrm{A}, \mathrm{b}}$ & $7.3^{\mathrm{a}}$ & ** \\
\hline & Middle & $62.9^{A, C}$ & $28.3^{\mathrm{B}, \mathrm{b}}$ & $8.8^{\mathrm{a}}$ & ** \\
\hline & Top & $60.4^{A, c}$ & $30.5^{\mathrm{B}, \mathrm{b}}$ & $9.2^{\mathrm{a}}$ & ** \\
\hline & SEM & 1.37 & 1.18 & 0.80 & \\
\hline & $P$ & * & * & NS & \\
\hline \multirow{5}{*}{ Age } & 24-29 weeks & $61.8^{A, C}$ & $28.8^{\mathrm{B}, \mathrm{b}}$ & 9.4 & $\star \star$ \\
\hline & 30-35 weeks & $71.5^{\mathrm{B}, \mathrm{C}}$ & $22.7^{\mathrm{A}, \mathrm{b}}$ & 5.9 & $\star \star$ \\
\hline & $36-42$ weeks & $61.1^{A, C}$ & $29.1^{\mathrm{B}, \mathrm{b}}$ & 9.8 & ** \\
\hline & SEM & 1.37 & 1.18 & 0.80 & \\
\hline & $P$ & $\star \star$ & * & NS & \\
\hline
\end{tabular}

NS: not significant, $P>0.05$; * $P<0.05$; *夫 $P<0.01$.

$A B$ means within a column followed by the different superscripts differ significantly.

${ }^{a b}$ means within a row followed by the different superscripts differ significantly.

\section{Conclusion}

In general, there were no differences in egg productivity and egg quality parameters among cage tiers. However, the studied parameters such as egg production and egg quality characteristics except shape index 
and albumen $\mathrm{pH}$ were affected by layer hens in the different age groups. Oviposition time is also significantly affected by tiers and age groups of laying hens.

\section{Acknowledgements}

The authors are thankful to the staff in the Department of Animal Science, Faculty of Agriculture, University of Gaziosmanpaşa, Tokat, Turkey.

\section{References}

Adams, A.W. \& Jackson, M.E., 1970. Effect of cage size and bird density on performance of six commercial strains of layers. Poult. Sci. 49, 1712-1719.

Ahmed, M. \& Singh, P., 2007. Estimates of genetic parameters for some economic traits in White Leghorn. Indian Poult. Sci. 42, 311-312.

Anderson, K.E., Tharrington, J.B., Curtis, P.A. \& Jones, F.T., 2004. Shell characteristics of eggs from historic strains of single comb white leghorn chickens and the relationship of shape to shell strength. Int. J. Poult. Sci. 3, 17-19.

Appleby, M.C., 1998. Modification of laying hens cages to improve behavior. Poult. Sci. 77, 1828-1832.

Awoniyi, T.A.M., 2003. The effect of housing on layer-chicken's productivity in the 3-tier cage. Int. J. Poult. Sci. 2, 438-441.

Baumgartner, J., Benková, J. \& Peškovicová, D., 2007. Effect of line, age and individuality on yolk cholesterol content and some other egg quality traits in Leghorn type yolk cholesterol selected hens. XVIII European Symposium on the quality of poultry meat and XII European Symposium on the quality of eggs and egg products, September 2 - 5. Prague. pp. 35-36.

Bell, D. \& Weaver, W., 2002. Commercial Chicken Meat and Egg Production. 5th ed. Cambridge, Massachusetts. Kluwer Academic Publisher.

Bozkurt, Z., Bayram, İ., Türkmenoğlu, İ. \& Aktepe, O.C., 2006. Effects of cage density and cage position on performance of commercial layer pullets from four genotypes. Turk. J. Vet. Anim. Sci. 30, 17-28.

Campbell, T.W., 1995. Avian hematology. In: Avian Hematology and Cytology. Ed: Campbell, T.W., lowa State University Press, Ames, lowa. pp. 3-19.

Campo, J.L. \& Prieto, M.T., 2009. Associations among fluctuating asymmetry, duration of tonic immobility, heterophil-to-lymphocyte ratio, and one-legged standing, crooked toes, or footpad dermatitis in chickens. Poult. Sci. 88, 65-71.

Carey, J.B., 1987. Effects of pullet-stocking density on performance of laying hens. Poult. Sci. 66, 1283-287.

Carey, J.B., Kuo, F.L. \& Anderson, K.E., 1995. Affects of cage population on the productive performance of layers. Poult. Sci. 74, 633-637.

Carmichael, N.L., Walker, A.W. \& Hughes, B.O., 1999. Laying hens in large flocks in a perchery system: Influence of stocking density on location, use of resources and behaviour. Br. Poult. Sci. 40, 165-176.

Charvátová, V. \& Tůmová, E., 2010. Time of oviposition and egg composition: A review. Sci. Agric. Bohemica. 41, 190-195.

Dávila, S.G., Campo, J.L., Gil, M.G., Prieto, M.T. \& Torres, O., 2011. Effects of auditory and physical enrichment on 3 measurements of fear and stress (tonic immobility duration, heterophil to lymphocyte ratio, and fluctuating asymmetry) in several breeds of layer chicks. Poult. Sci. 90, 2459-2466.

De Boer, I.J.M. \& Cornelissen, A.M.G., 2002. A method using sustainability indicators to compare conventional and animal friendly egg production systems. Poult. Sci. 81, 173-181.

Doyon, G., Bernier-Cardou, M., Hamilton, R.M.G., Castalgne, F. \& Randall, C.J., 1986. Egg quality 2. Albumen quality of eggs from five commercial strains of white leghorn hens during one year of lay. Poult. Sci. 65, 63-66.

DSM, 2013. Yolk color fan. Available at www.dsmnutritionalproducts.com (accessed: 10 February 2013).

Duncan, I.J.H., 2001. The pros and cons of cages. Worlds Poult. Sci. J. 57, 381-390.

Efil, H. \& Sarica, M., 1998. The effects of different light sources and lighting periods on layers production traits, feed consumption, and egg quality in open poultry houses. Turk. J. Vet. Anim. Sci. 22, 197-204.

Elston, J.J., Beck, M.M., Kachman, S.D. \& Scheideler, S.E., 2000. Laying hen behavior. 1. Effect of cage type and startle stimuli. Poult. Sci. 79, 471-476.

Fidan, E.D. \& Nazlıgül, A., 2012. The effect of cage position and density on some production on traits in denizli chickens. Anim. Health Prod. Hyg. 1, 31-37.

Grover, R.M., Anderson, D.L., Damon, R.A. \& Ruggles, L.H., 1972. The effects of bird density, dietary energy, light intensity and cage level on the reproductive performance of heavy type chickens in wire cages. Poult. Sci. 51, 565-575.

Hamilton, R.M.G., 1982. Methods and factors that affect the measurement of egg shell quality. Poult. Sci. 61, 2022-2039. 
Harms, R.H., Rossi, A.F., Sloan, D.R., Miles, R.D. \& Christmas, R.B., 1990. A method for estimating shell weight and correcting specific gravity for egg weight in eggshell quality studies. Poult. Sci. 69, 48-52.

Hughes, B.O., Wilson, S., Appleby, M.C. \& Smith, S.F., 1993. Comparison of bone volume and strength as measures of skeletal integrity of caged laying hens with access to perches. Res. Vet. Sci. 54, 202-206.

Ingram, D.R., Hatten III, L.F. \& Homan, K.D., 2008. A study on the relationship between eggshell color and eggshell quality in commercial broiler breeders. Int. J. Poult. Sci. 7, 700-703.

Jackson, M.E. \& Waldroup, P.W., 1987. Effects of cage level (tier) on the performance of White Leghorn chickens. Poult. Sci. 66, 907-909.

Jin, Y.H., Lee, K.T., Lee, W.I. \& Han, Y.K., 2011. Effects of storage temperature and time on the quality of eggs from laying hens at peak production. Asian-Austral. J. Anim. Sci. 24, 279-284.

Johnston, S.A. \& Gous, R.M., 2007. Modelling the changes in the proportion of the egg components during a laying cycle. Br. Poult. Sci. 48, 347-353.

Jones, R.B., 1986. The tonic immobility reaction of the domestic fowl: a review. World's Poult. Sci. J. 42, 82-96.

Karaman, S., Sekeroglu, A. \& Duman, M., 2013. Physical characteristics and performance of Laying hens caged in different tiers and environmental parameters of each tier. Am. Soc. Agric. Biol. Eng. 56, 321-328.

Ledvinka, Z., Zita, L. \& Klesalová, L., 2012. Egg quality and some factors influencing it: a review. Sci. Agric. Bohemica. 43, 46-52.

Mills, A.D. \& Faure, J.M., 1991. Divergent selection for duration of tonic immobility and social reinstatement behavior in Japanese quail (Coturnix coturnix japonica) chicks. J. Comp. Psychol. 105, 25-38.

Nazlıgül, A., Ertuğrul, O., Orman, M. \& Aksoy, T., 1995. Some production characteristics of layers from different genetic origins (Gallus domesticus) and effects of different cage position on egg production and egg weight traits. Turk. J. Vet. Anim. Sci. 19, 339-347.

Nicol, C., 1995. Environmental enrichment- for birds. In: Environmental Enrichment Information Resources for Laboratory Animals: 1965-1995: Birds, Cats, Dogs, Farm Animals. Ferrets. Rabbits, and Rodents. AWIC Resource Series No. 2. USDA, Beltsville. MD. pp. 1-25.

Nordstrom, J.O. \& Ousterhout. L.E., 1982. Estimation of shell weight and thickness from egg specific gravity and egg weight. Poult. Sci. 61, 1991-1995.

North, M.O., 1984. Breeder Management. In: Commercial Chicken Production Manual. The Avi. Publishing Company. Inc. Westport, Connecticut, 240-321.

Onbasilar, E.E. \& Aksoy, F.T., 2005. Stress parameters and immune response of layers under different cage floor and density conditions. Livest. Prod. Sci. 95, 255-263.

Patterson, P.H. \& Siegel, H.S., 1998. Impact of cage density on dullet performance and blood paramaters of stress. Poult. Sci. 77, 32-40.

Rizzi, C. \& Chiericato, G.M., 2005. Organic farming production. Effect of age on the productive yield and egg quality of hens of two commercial hybrid lines and two local breeds. Ital. J. Anim. Sci. 4, 160-162.

Sahin, S., 2012. Effects of cage location and tier level on performance and egg quality traits of laying hens. J. Anim. Vet. Adv. 11, 2380-2383.

Rodenburg, T.B., Bracke, M.B.M., Berk, J., Cooper, J., Faure, J.M., Guemene, D., Guy, G., Harlander, A., Jones, T., Knierim, U., Kuhnt, K., Pingel, H., Reiter, K., Serviere, J. \& Ruis, M.A.W., 2005. Welfare of ducks in European duck husbandry systems. World's Poult. Sci. J. 61, 633-646.

Roush, W.B.T., 1981. 159 calculator program for Haugh unit calculation. Poult. Sci. 60, 1086-1088.

Sekeroglu, A., Sarica, M., Demir, E., Ulutas, A.Z., Tilki, M., Saatci, M. \& Omed, H., 2010. Effects of different housing systems on some performance traits and egg qualities of laying hens. J. Anim. Vet. Adv. 9, 1739-1744.

Siegel, H.S., 1985. Immunological responses as indicators of stress. World's Poult. Sci. J. 41, 36-44.

Silversides, F.G., 1994. Is the Haugh unit correlation for egg weights valid for eggs stored at room temperature? Poult. Sci. 73, 50-55.

Silversides, F.G. \& Villeneuve, P., 1994. Is the haugh unit correction for egg weight valid for eggs stored at room temperature? Poult. Sci. 73, 50-55.

SPSS 16.0, 2010. Statistical Package in Social Sciences for Windows. Statistical Innovations Inc., Chicago, USA.

Tauson, R., 1998. Health and production in improved cage designs. Poult. Sci. 77, 1820-1827.

TSE, 2009. TS 1068: Chicken eggs in shell. Ankara, Turkey: Turkish Standards Institution (TSE).

Tůmová, E. \& Ledvinka, Z., 2009. The effect of time of oviposition and age on egg weight, egg components weight, and eggshell quality. Arch. Geflügelkd. 73, 110-115.

Tůmová, E. \& Gous, R.M., 2012. Interaction between oviposition time, age, and environmental temperature and egg quality traits in laying hens and broiler breeders. Czech J. Anim. Sci. 57, 541-549. 
Tůmová, E., Zita, L., Hubený, M., Skřivan, M. \& Ledvinka, Z., 2007. The effect of oviposition time and genotype on egg quality characteristics in egg type hens. Czech J. Anim. Sci. 52, 26-30.

Tůmová, E., Englmaierová, M., Ledvinka, Z. \& Charvátová, V., 2011. Interaction between housing system and genotype in relation to internal and external egg quality parameters. Czech J. Anim. Sci. 56, 490-498.

Van den Brand, D., Parmentier, H. \& Kemp, B., 2004. Effects of housing system (outdoor vs cages) and age of laying hens on egg characteristics. Br. Poult. Sci. 45, 745-752.

Vestergaard, K.S., Skadhauge, E. \& Lawson, L.G., 1997. The stress of not being able to perform dustbathing in laying hens. Physiol. Behav. 62, 413-419.

Vits, A., Weitzenhurger, D. \& Distl, O., 2005. Comparison of different housing systems for laying hens in respect to economic, health and welfare parameters with special regard to organized cages. Dtsch. Tierarztl. Wochenschr. 112, 332-342.

Wei, R., Bitgood, J.J. \& Dentine, M.R., 1992. Inheritance of tinted eggshell colours in white-shell stocks. Poult. Sci. 71, 406-418.

Wells, R.G., 1972. A comparison of the shell strength of eggs from battery and deep-litter units. Br. Poult. Sci. 13, 410-421.

Yang, H.M., Wang, Z.Y. \& Lu, J., 2009. Study on the relationship between eggshell colors and egg quality as well as shell ultrastructure in Yangzhou chicken. Afr. J. Biotechnol. 8, 2898-2902.

Yannakopoulos, A.L \& Tserveni-Gousi, A.S., 1987. Effect of egg weight and shell quality on day-old duckling weight. Arch Geflügelkd. 51, 157-159

Yıldırım, A., Şekeroğlu, A., Eleroğlu, H., Şen, M.I. \& Duman, M., 2013. Effects of Korean ginseng (Panax ginseng C.A. Meyer) root extract on egg production performance and egg quality of laying hens. S. Afr. J. Anim. Sci. 43, 194-207.

Yıldırım, A., Şekeroğlu, A., Koç, H., Eleroğlu, H., Tahtalı, Y., Şen, M.I., Duman, M. \& Genç, N., 2014. The effect of dry caper (Capparis spinosa) fruit on egg production and quality characteristics of laying hens. Pak. J. Agri. Sci. 51, 217-224.

Yıldız, A., Laçin, E., Hayirli, A. \& Macit, M., 2006. Effects of cage location and tier level with respect to light intensity in semiconfined housing on egg production and quality during the late laying period. J. Appl. Poult. Res. 15, 355-361.

Zemková, L'., Simeonovová, J., Lichovníková, M. \& Somerlíková, K., 2007. The effects of housing systems and age of hens on the weight and cholesterol concentration of the egg. Czech J. Anim. Sci. 52, 110-115.

Zita, L., Tůmová, E. \& Štolc, L., 2009. Effects of genotype, age and their interaction on egg quality in brownegg laying hens. Acta Vet. Brno. 78, 85-91. 